\title{
In-Space Transportation for NASA's Evolvable Mars Campaign
}

\author{
Thomas K. Percy ${ }^{1}$ \\ SAIC, Jacobs ESSSA Group, Huntsville, AL, 35806 \\ Melissa McGuire ${ }^{2}$ \\ NASA Glenn Research Center, Cleveland, OH, 44135 \\ and \\ Tara Polsgrove ${ }^{3}$ \\ NASA Marshall Space Flight Center, Huntsville, AL, 35812
}

\begin{abstract}
As the nation embarks on a new and bold journey to Mars, significant work is being done to determine what that mission and those architectural elements will look like. The Evolvable Mars Campaign, or EMC, is being evaluated as a potential approach to getting humans to Mars. Built on the premise of leveraging current technology investments and maximizing element commonality to reduce cost and development schedule, the EMC transportation architecture is focused on developing the elements required to move crew and equipment to Mars as efficiently and effectively as possible both from a performance and a programmatic standpoint. Over the last 18 months the team has been evaluating potential options for those transportation elements. One of the key aspects of the EMC is leveraging investments being made today in missions like the Asteroid Redirect Mission (ARM) mission using derived versions of the Solar Electric Propulsion (SEP) propulsion systems and coupling them with other chemical propulsion elements that maximize commonality across the architecture between both transportation and Mars operations elements. This paper outlines the broad trade space being evaluated including the different technologies being assessed for transportation elements and how those elements are assembled into an architecture. Impacts to potential operational scenarios at Mars are also investigated. Trades are being made on the size and power level of the SEP vehicle for delivering cargo as well as the size of the chemical propulsion systems and various mission aspects including Inspace assembly and sequencing. Maximizing payload delivery to Mars with the SEP vehicle will better support the operational scenarios at Mars by enabling the delivery of landers and habitation elements that are appropriately sized for the mission. The purpose of this investigation is not to find the solution but rather a suite of solutions with potential application to the challenge of sending cargo and crew to Mars. The goal is that, by building an architecture intelligently with all aspects considered, the sustainable Mars program wisely invests limited resources enabling a long-term human Mars exploration program.
\end{abstract}

\section{Nomenclature}

C3 = Escape Energy $\left(\mathrm{km}^{2} / \mathrm{s}^{2}\right)$

$R \quad=$ Distance from the Sun

$\Delta V \quad=$ Propulsive Delta Velocity $(\mathrm{m} / \mathrm{s})$

\footnotetext{
${ }^{1}$ Aerospace Engineer, MSFC Advanced Concepts, 6723 Odyssey Dr, Huntsville, AL 35806, AIAA Member.

${ }^{2}$ Aerospace Engineer, Mission Architecture and Analysis Branch, M.S. 162-2 NASA Glenn Research Center 21000 Brookpark Road, Cleveland, Ohio 44135, AIAA Member.

${ }^{3}$ FPPO HAT Lead, Exploration Missions and Systems Office, NASA MSFC FP30, Huntsville, AL 35812, AIAA Member.
} 


\section{Introduction}

$\mathrm{N}$ ASA is currently developing a new long-term strategy to expand human exploration of space beyond the confines of low Earth orbit and into the solar system. This Pioneering Space strategy focuses on evolving space exploration capabilities from our current Earth Reliant state, through a cis-lunar Proving Ground of technology demonstrations and incrementally more challenging human space flights, to an Earth Independent state where crews of astronauts live and work on the surface of Mars. To provide the context for identifying and prioritizing technology investments along that path to Mars, the Evolvable Mars Campaign (EMC) is supporting an ongoing series of architectural trade analyses. The EMC is integrating teams from across NASA to investigate common capability needs across three broad areas; transportation, habitation, and destination systems. At its core, the EMC is not a study to define the next Mars design reference mission, but rather a series of ongoing studies designed to understand the potential future paths for human Mars exploration within the context of the Pioneering Space strategy, placing emphasis on affordability, sustainability, and reusability.

The Pioneering Space strategy is built on a set of key principles for a sustainable and affordable space program that help ensure NASA's investments efficiently and effectively achieve the nation's space exploration goals. These principles include:

- Implementable in the near-term with the buying power of current budgets and in the longer term with budgets commensurate with economic growth;

- Exploration enables science and science enables exploration, leveraging robotic expertise for human exploration of the solar system

- Application of high Technology Readiness Level (TRL) technologies for near term missions, while focusing sustained investments on technologies and capabilities to address challenges of future missions;

- $\quad$ Near-term mission opportunities with a defined cadence of compelling and integrated human and robotic missions providing for an incremental buildup of capabilities for more complex missions over time;

- Opportunities for U.S. commercial business to further enhance the experience and business base;

- Multi-use, evolvable space infrastructure, minimizing unique major developments, with each mission leaving something behind to support subsequent missions; and

- Substantial new international and commercial partnerships, leveraging the current International Space Station partnership while building new cooperative ventures.

The EMC team has been working to identify and evaluate a suite of potential mission architectures, integrating transportation, habitation, and destination systems in a mission construct that supports successful human Mars exploration within the guidelines of the Pioneering Space strategy. Several papers are being published at the AIAA Space 2015 conference by these various teams to provide an overall picture of the breadth and depth of the ongoing EMC work.

This paper provides a snapshot of ongoing analyses of one suite of transportation architecture options being investigated as part of the EMC. Many of the key principles of the Pioneering Space strategy revolve around building a sustainable exploration program by leveraging current investments and high Technology Readiness Level (TRL) components, evolving capabilities and infrastructure, and minimizing unique developments to the greatest extent possible. In the discipline of transportation architecting, these principles are the root of the overarching ground rule that all Mars architectures will use Solar Electric Propulsion (SEP) technologies evolved from the Asteroid Redirect Mission (ARM). There are many potential ways to meet this ground rule and, within the EMC, two general architectures are being investigated. This paper will focus on the development of architectures that split the delivery of cargo and crew, using two distinctly different transportation technologies for those two roles. The cargo in these architectures is delivered by SEP while the crew will fly on more traditional chemical propulsion systems. This paper outlines the general mission architecture approach to combining these two delivery methods. Detailed discussion of the design of the trajectories and stages for both delivery methods is provided along with an overview of trades completed and a comparison of results to date. 


\section{A Brief Overview of the Evolvable Mars Campaign}

The EMC does not seek to prescribe a particular path for exploring Mars but rather seeks to better clarify and understand the various paths available to help guide the next 20 years of technology developments as NASA moves closer to its long-term goal of sending humans to Mars. A small set of general ground rules and constraints guide the various trade analyses and design studies being performed. These ground rules include:

- Humans to the Mars System by mid-2030’s

- Propulsion technology will utilize solar-electric systems extensible from the Asteroid Redirect Vehicle (ARV) spacecraft bus

- Earth-to-Orbit launch vehicle SLS Block 2B launch vehicle and Orion spacecraft will be available

- Vehicle checkout and assembly (aggregation) in a lunar distant retrograde orbit (LDRO) to leverage infrastructure established during Proving Ground phase

- Crew of four to Mars system assumed

- Crewed vehicle reusability for sustainability and potential cost advantages where reasonable

The shaded portion of the trade tree in Figure 1 shows where the EMC resides within the general trade space of Mars architectures. Similar paths can be mapped through this trade space to represent alternative Mars exploration approaches such as NASA's DRA 5.0. ${ }^{1}$ Within the EMC branch of the general mission trade space, two different general transportation architecture approaches are being investigated. Both leverage the investments in SEP being made to support the ARM mission. An operational trade space is mapped using the trade tree in Figure 2 that outlines the key differences between these two general transportation approaches.

\begin{tabular}{|c|c|c|c|c|}
\hline Mission Type & Flyby & Short Stay & Long Stay & \\
\hline Surface Mission & None & Minimal & Full & \\
\hline Surface Campaign & Single-Site, Build-Up & Multi-Site, Independent & & \\
\hline Mars Capture Method & Propulsive Capture All & Aerocapture Some Cargo & Aerocapture All Cargo & Aerocapture All \\
\hline Reuse & None & Partial & Full & \\
\hline ISRU & None & At Mars & At Earth & \\
\hline Primary In-Space Propulsion & Chemical & Electric & Electric/Chem & NTP \\
\hline
\end{tabular}

Figure 1. The Mars Capability/Mission Definition Trade Space. This trade tree shows the suite of potential options for performing a Mars exploration campaign. The green highlighted path defines the general characteristics of the Evolvable Mars Campaign mission approach.

At the core of the SEP Hybrid options is a hybrid spacecraft that uses both SEP and traditional chemical propulsion in a single spacecraft to deliver both crew and cargo to Mars. This approach uses higher-thrust chemical propulsion for operations within the gravity wells of Earth and Mars while taking advantage of the high-efficiency electric propulsion system to increase delivery mass. This spacecraft is fully reusable, returning to the LDRO for refurbishment and refueling.,3

The second general transportation architecture approach is referred to as the "SEP Chemical" approach. This approach splits the functions of crew and cargo delivery into two distinct transportation approaches. Highefficiency solar electric propulsion is used to deliver all cargo to Mars. These cargo delivery flights, while longer in duration, can be achieved in single launches using the Space Launch System (SLS) Block 2. While these slower trajectories are acceptable for cargo elements, the crew flight duration must be significantly shorter to minimize the impacts of zero gravity and prolonged radiation exposure. The SEP Chemical architectures employ Methane Cryogenic Propulsion Stages (MCPS) for these crew flights, using more traditional high-thrust, conjunction-class trajectories. The SEP stages in the SEP Chemical approach are one generation removed from the current ARM vehicle and the MCPS design leverages common engine development with the Mars lander to reduce chemical stage development costs. 


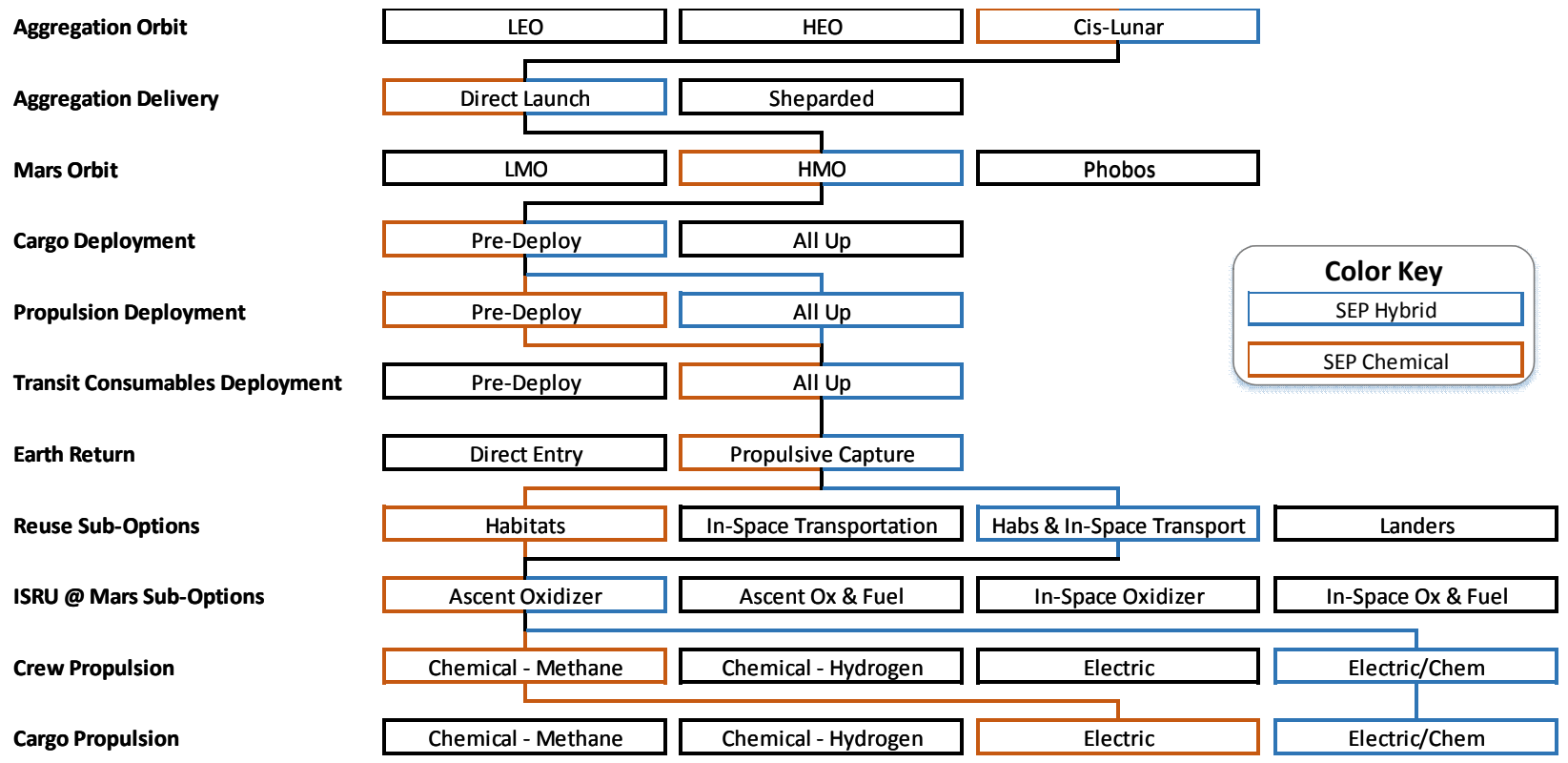

Figure 2. The Mars Mission Operational Trade Space. The two general architectural approaches being investigated in the EMC are distinguished by their place in the Operational Trade space. The SEP Hybrid architecture is highlighted in blue and the SEP Chemical in orange.

A quick comparison of the two general architecture approaches reveals that they differ only in a few key areas. Both leverage infrastructure in cis-lunar space for aggregation of elements and use SLS to get there. Both predeploy cargo and carry all crew consumables for the crew flights to and from Mars. Both use high Mars parking orbits and perform propulsive capture upon Earth return to support the reuse of the transit habitat. While both architectures reuse the habitat, only the SEP Hybrid architectures have baselined reuse of the transportation stage. This option will be traded in the SEP Chemical architecture trade space in future analyses but reuse of the transportation systems does require in-space propellant transfer, adding operational complexity to those architectures. Another key discriminator between these two architectures is the pre-deployment of propulsion elements. The SEP Hybrid spacecraft takes advantage of high-efficiency propulsion technology to avoid staging. The use of chemical propulsion for crew delivery in the SEP Chemical architecture necessitates staging with one MCPS being used for each of the major propulsive maneuvers in the crew flights. Pre-deploying the Earth return stages using the higher-efficiency SEP stages greatly reduces the crew stack Earth departure mass and the number of stages required to get to Mars. While this increases this risk posture of these architectures by requiring the crew the rendezvous at Mars with the stages needed to return to Earth, the performance benefits are substantial.

\section{General Architecture Description}

The SEP Chemical architecture uses a traditional chemical propulsion approach to crew delivery and places technology development focus on long-duration cryo fluid management. Cargo, including Earth return propulsion, landers, and exploration equipment, is pre-deployed using high-efficiency SEP stages. The following section provides an overview of the current baseline transportation architecture and shows how these two propulsion technologies are combined to support the EMC.

\section{A. Mission Sequence of the Campaign}

The SEP Chemical architecture outlines a three mission sequence that spans over a decade of flights to Mars and supports the exploration of the Martian moon Phobos and the eventual landing of humans on the surface of Mars. Each of the three missions in the campaign employ a split approach, pre-deploying cargo ahead of the flights that deliver the mission crew. The pre-deployed elements vary from mission to mission depending on the mission goals and the mission flight year however, they generally fall into one of three categories; destination systems, Mars surface landers, or Earth return propulsion elements. All pre-deployed elements are delivered using an SEP stage while all crew flights are completed using a series of Methane Cryogenic Propulsion Stages (MPCS). Many of the 
missions involve aggregation of mission elements in a Lunar Distant Retrograde Orbit (LDRO) prior to Earth departure. All elements are launched on SLS Block 2 launch vehicles, using both advanced boosters and the Exploration Upper Stage (EUS).

The three mission sequence begins with a crewed mission to explore the surface of the Martian moon Phobos in 2033. This is followed in 2039 by the first mission to land humans on the surface of Mars. In 2043, humans return to the Martian surface and continue exploration of the red planet. While the Pioneering Space strategy embraces sustainability as one of its key principles, implying continued exploration of the Martian surface after 2043, the three mission sequence at the focus of the EMC represents the critical first decade of human Martian exploration and will drive many of the technology development decisions to be made over the next two decades. Figure 3 provides an overview of the general flight sequence for each of the three missions in the EMC. SEP flights are represented by blue lines, crew flights in green, SLS launches in red, and loiter time in yellow.

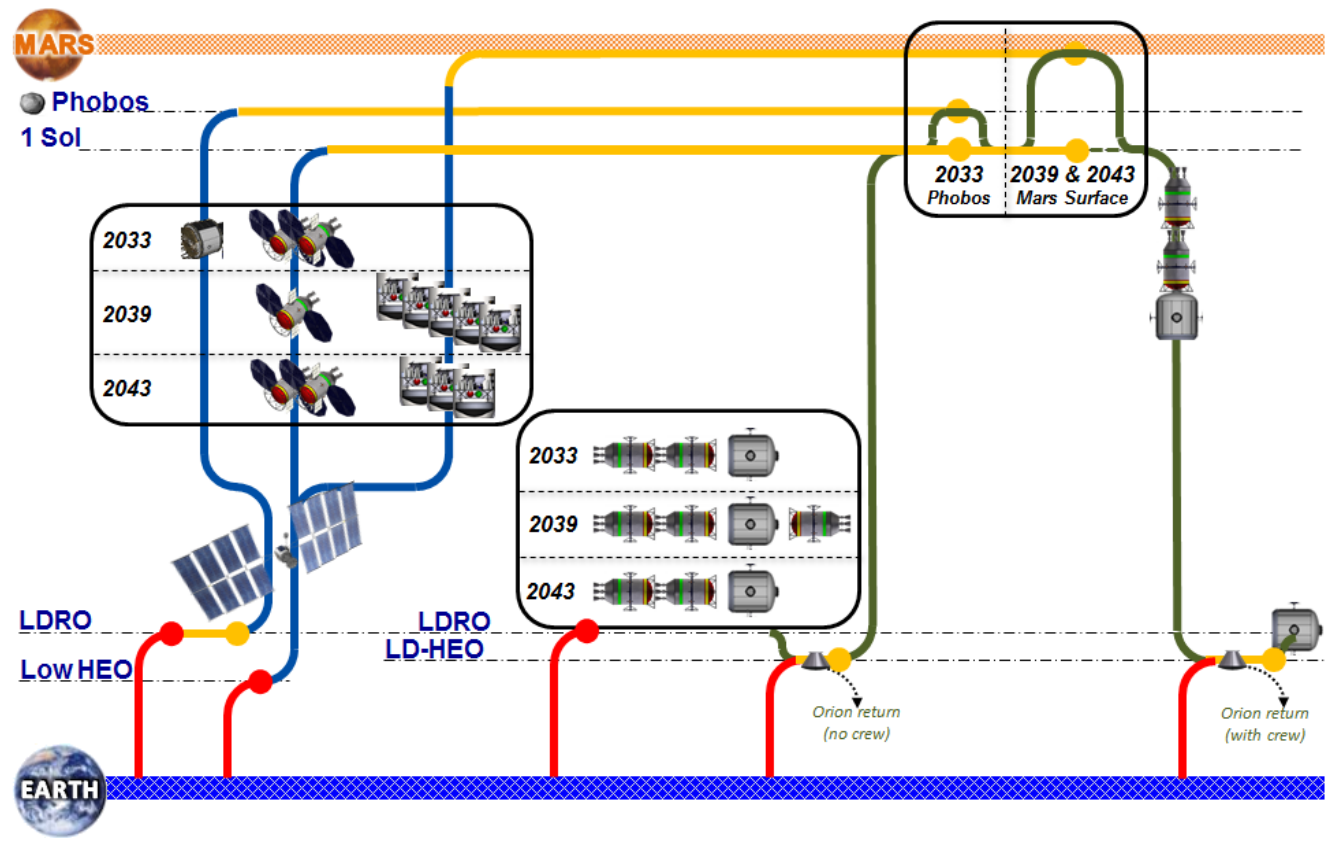

Figure 3. The Split SEP-Chemical Architecture. This generalized bat chart provides an overview of the flight sequence and flight manifests for the three mission sequence that makes up the SEP Chemical architecture within the Evolvable Mars Campaign.

The 2033 mission to Phobos begins with the pre-deployment of Phobos exploration systems and Earth return propulsion elements. The Phobos exploration systems include a habitat and pressurized crew exploration vehicle which are launched directly to LDRO for checkout. A SEP stage is also launched to LDRO. After checkout of the Phobos habitat is complete, the SEP stage begins the journey to Phobos. After 1457 days of flight time, the Phobos habitat and expended SEP stage land on Phobos using the SEP stage Reaction Control Systems (RCS) propulsion system. The SEP stage remains attached to the habitat to provide operational power while on the surface of Phobos. The delivery of the Phobos habitat is currently the only SEP pre-deployment flight which requires aggregation in Earth orbit. This is largely due to the mass of the Phobos exploration systems and the energy required to spiral down into the Martian gravity well to get to Phobos.

Two more pre-deployment flights are completed to support the 2033 Phobos mission. In each of these predeployment flights, a single SLS launch delivers an SEP stage and an MCPS to an elliptical Earth orbit where the SEP stage begins the slow spiral climb out of Earth's gravity well. This stack performs a lunar swing-by maneuver, converting the stack escape energy from $-2 \mathrm{~km}^{2} / \mathrm{s}^{2}$ to $+2 \mathrm{~km}^{2} / \mathrm{s}^{2}$ and the SEP vehicle then continues to thrust to Mars delivering the payload to a 1 Sol parking orbit where it will await the arrival of the crew. One SEP flight delivers the Trans-Earth Injection (TEI) stage while the other SEP flight delivers both the Earth Orbit Insertion (EOI) stage and the Mars Crew Taxi. These pre-deployment flights take 3-4 years each.

While elements are being pre-deployed to Mars on low-thrust trajectories, assembly begins on the crew stack. All of the crew flights are completed with a set of MCPS which are aggregated with the transit habitat in LDRO. 
For the 2033 Phobos mission, the crew stack consists of a deep space habitat, an MCPS for Mars Orbit Insertion (MOI), and an MCPS for Trans-Mars Injection (TMI). Once this stack is assembled, it departs LDRO for a Lunar Distant High Elliptical orbit (LDHEO), an orbit with a perigee of $400 \mathrm{~km}$ and an apogee at lunar distance. The crew meets the stack in the LDHEO, transfers from their Orion capsule into the deep space habitat, and jettisons the Orion capsule. At perigee, the TMI stage performs its burn sending the crew stack on a 231 day flight to Mars. The MOI stage performs orbit capture at Mars, parking the transit hab in a 1 Sol parking orbit. Once in the parking orbit, the transit hab docks with the pre-deployed Earth return stages and the crew transfers into the Mars Crew Taxi for the 2day flight from the 1 Sol parking orbit to Phobos. The crew spends the bulk of its 528 day Mars stay time living and working out of the Phobos habitat while the crew transportation stack is repositioned to align its parking orbit with the Earth return trajectory.

At the end of the Phobos mission, the crew taxi ferries the crew back to the orbiting transit habitat and transportation stack. The TEI MCPS injects the crew stack into a 198 day Earth return trajectory. Upon Earth arrival, the EOI MCPS performs a braking burn that places the transit habitat back into the LDHEO where it rendezvous with a new Orion capsule. The crew transfers into the Orion capsule and returns to Earth while the transit habitat continues on to its ultimate destination, the LDRO, where it will be refurbished and reoutfitted for the next crew flight to Mars.

While the crew is exploring the surface of Phobos, pre-deployment flights begin to deliver elements required for the 2039 Mars landing missions. For both Mars surface missions, the SEP stages are used to pre-deploy Earth return stages and Mars landers. Delivery of the Earth return stages is similar to that of the Phobos mission, with flight durations around 3 years. Landers are delivered using a similar, single-launch approach. The SEP stage flies a spiral Earth departure trajectory followed by a lunar swing-by to increase Earth departure energy. However, the landers are delivered to Mars via aerocapture, each equipped with an aeroentry system. The SEP vehicles deliver the landers to a Mars arrival velocity of $5.2 \mathrm{~km} / \mathrm{s}$ and fly-by Mars while the landers aerocapture into the Martian system. This saves several years of flight time by eliminating any SEP flight within the Martian gravity well. Delivery of the 5 landers required for the 2039 Mars surface mission begins in 2034 and each flight takes approximately 3.5 years.

The crew departs for Mars in 2039 using two MPCS, one for TMI and a second for MOI. Due to the lower energy of the 2039 crew trajectory, the crew stack also contains the EOI MCPS, thus eliminating the need for an SEP flight to pre-deploy that element. This flight to Mars will take 350 days. After propulsively capturing into a 1 Sol orbit around Mars, the crew stack docks with the TEI MCPS and a lander. The crew then transfers into the Mars lander and departs for the Martian surface. While the crew is conducting surface operations, the crew transit stack is repositioned. After 300 days of surface operations, the crew ascends in the Mars Ascent Vehicle, transfers into the transit habitat and returns to Earth via the same sequence of operations used in the 2033 mission. The Earth return flight takes 298 days.

The landers and propulsion elements required to support the 2043 Mars surface mission actually begin their journey to Mars before the 2039 crew departs for Mars. In 2038, SEP flights begin to pre-deploy the Earth return stages and landers for the 2043 mission. Three additional landers are required for the 2043 mission which will return to the same landing site as the 2039 mission in order to build upon the infrastructure already in place. In 2043 the crew will depart for Mars, taking a 289 day journey to rendezvous in a 1 Sol orbit with their Earth return stages and a new lander. The crew will spend 358 days at Mars before taking a 356 day journey back to Earth. In all, the three mission sequence employs 14 SEP stages, 12 MCPS, 8 Landers, and a single transit habitat. 


\section{B. Supporting Elements}

There are many flight elements required to support the EMC. While transportation is the primary focus of this paper, significant work has gone into the definition and design of elements across all aspects of the campaign. Phobos surface exploration elements, including a 500-day habitation module and a Pressurized Excursion Vehicle (PEV) have been designed to support the 2033 Phobos exploration mission. ${ }^{4}$ The Phobos mission also requires a crew taxi to transport crew to and from the Phobos habitat. Significant work has also been completed in defining the transit habitat that supports the crew during their interplanetary transfers as well as the consumables and trash disposal requirements. Another key element, and one that drives much of the transportation architecture work, is the Mars lander. ${ }^{5}$ Several lander concepts of varying size have been generated and the surface exploration team has developed alternative manifests for delivering the surface equipment on those landers. ${ }^{6}$ Naturally, the smaller the lander is the more landers are required to complete a given surface mission. The baseline lander concept is one that delivers $18 \mathrm{t}$ of payload to the Martian surface. To complete the 2 surface exploration missions in the EMC, 8 landers of this size must be delivered to Mars. The current mass and configuration of each of these support elements is provided in Table 1.

\section{Overall Performance Summary}

An overall summary of current chemical performance values is provided in Table 2. This data outlines the crew flights required for each of the 3 missions in the EMC. There are a few items to take note of in this table. First is the Mars stay times associated with each of the three opportunities. Due to the nature of the high-thrust trajectories, the landing opportunities in 2039 and 2043 offer only approximately 350 days of stay time at Mars. This reduces the surface stay time to significantly less than the typical 500-day assumption. The other item of note is that on all opportunities a single stage is dedicated to each major burn in the architecture. This is largely due to the limitations of pre-deployment that are a function of SEP performance and the desire to reduce flight times to Mars. This approach has some positive impacts to MCPS related to stage dormancy which will be discussed in Section V.

Table 2. Crew Flight Performance Summary. Crew stack performance summary for each of the three missions in the EMC SEP-Chemical baseline architecture.

\begin{tabular}{|c|c|c|c|c|}
\hline \multirow{2}{*}{\multicolumn{2}{|c|}{ Mission Decription }} & 2033 & 2039 & 2043 \\
\hline & & Mars Orbit / Phobos & Long Surface Stay 1 & Long Surface Stay 2 \\
\hline \multirow{2}{*}{ TMI } & $\Delta \mathrm{V}(\mathrm{m} / \mathrm{s})$ & 983.0 & 692.0 & 547.0 \\
\hline & Stage Mass ( $t$ ) (Wet/Dry) & $44.3 / 8.1$ & $37.5 / 7.5$ & $26.4 / 6.9$ \\
\hline \multirow[b]{2}{*}{ MOI } & $\Delta V(\mathrm{~m} / \mathrm{s})$ & 1244.9 & 888.0 & 1082.0 \\
\hline & Stage Mass (t) (Wet/Dry) & $34.8 / 8.1$ & $31.9 / 7.5$ & $29.1 / 6.9$ \\
\hline \multirow[b]{2}{*}{ TEI } & $\Delta \mathrm{V}(\mathrm{m} / \mathrm{s})$ & 1095.1 & 989.0 & 630.0 \\
\hline & Stage Mass (t) (Wet/Dry) & $36.6 / 8.1$ & $33.0 / 7.5$ & $28.0 / 6.9$ \\
\hline \multirow[b]{2}{*}{ DROI } & $\Delta \mathrm{V}(\mathrm{m} / \mathrm{s})$ & 549.1 & 513.0 & 1427.0 \\
\hline & Stage Mass ( $t$ ) (Wet/Dry) & $17.7 / 8.1$ & $18.3 / 7.5$ & $30.6 / 6.9$ \\
\hline \multicolumn{2}{|c|}{ Hab Mass (t) / Duration (d) } & $41.2 / 957.0$ & $41.3 / 977.0$ & $41.6 / 1003.0$ \\
\hline \multicolumn{2}{|c|}{ Mission Time (d) (out/stay/back) } & $231 / 528 / 198$ & $350 / 329 / 298$ & $289 / 358 / 356$ \\
\hline
\end{tabular}

Table 3 provides a summary of the SEP performance for all pre-deployment flights. Flight times range from 2 years to 4.1 years with two distinct Mars delivery schemes. When delivering landers to Mars, the SEP stage releases the landers prior to Mars arrival and the landers perform an aerocapture maneuver to arrive in the 1 Sol parking orbit while the SEP stage performs a fly-by of Mars and ends its mission in heliocentric space. All other pre-deployment deliveries use the SEP to spiral down to the Mars destination orbit. This results in a requirement for more power in order to minimize spiral time at Mars. 
Table 3. Pre-Deployment Flight Performance Summary. SEP stage performance summary for each of the three missions in the EMC SEP-Chemical baseline architecture.

\begin{tabular}{|c|c|c|c|c|}
\hline & $\begin{array}{l}\text { Pre-Deployed } \\
\text { Element }\end{array}$ & Destination & $\begin{array}{c}\text { Total Flight } \\
\text { Time (yrs) }\end{array}$ & $\begin{array}{r}\text { Xenon } \\
\text { Load (t) }\end{array}$ \\
\hline \multirow{3}{*}{$\begin{array}{c}2033 \\
\text { Phobos } \\
\text { Mission } \\
\end{array}$} & TEl Stage & $1 \mathrm{Sol}$ & 4.1 & 19.1 \\
\hline & EOI Stage \& Taxi & $1 \mathrm{Sol}$ & 2.8 & 13.4 \\
\hline & Phobos Hab \& PEV & Phobos & 4.0 & 19.2 \\
\hline \multirow{6}{*}{$\begin{array}{c}2039 \\
\text { Landing } \\
\text { Mission }\end{array}$} & Lander 1 & Aerocapture & 3.7 & 16.6 \\
\hline & Lander 2 & Aerocapture & 3.7 & 16.6 \\
\hline & Lander 3 & Aerocapture & 3.7 & 16.6 \\
\hline & Lander 4 & Aerocapture & 3.7 & 16.6 \\
\hline & Lander 5 & Aerocapture & 3.7 & 16.6 \\
\hline & TEl Stage & 1 Sol & 3.2 & 15.3 \\
\hline \multirow{5}{*}{$\begin{array}{c}2043 \\
\text { Landing } \\
\text { Mission }\end{array}$} & Lander 1 & Aerocapture & 3.7 & 16.6 \\
\hline & Lander 2 & Aerocapture & 3.7 & 16.6 \\
\hline & Lander 3 & Aerocapture & 3.7 & 16.6 \\
\hline & TEl Stage & $1 \mathrm{Sol}$ & 2.0 & 9.9 \\
\hline & EOI Stage & $1 \mathrm{Sol}$ & 2.6 & 12.7 \\
\hline
\end{tabular}

The pre-deployment of the Phobos exploration elements is a unique flight. Due to the large mass of the Phobos exploration elements and the large energy requirement to spiral into Phobos' orbit, a full SEP flight through the Earth spiral, out to Mars, and spiraling down to Phobos results in extremely long total flight times. To avoid this issue, the Phobos exploration elements and their SEP stage are delivered in two separate SLS launches directly to the LDRO. Once in LDRO, the Phobos hab is checked out and docked to the SEP stage. The stack then begins its journey to Mars from LDRO, reducing the flight time to 4 years and saving over 3 years of total flight time.

\section{The Evolution of SEP: Cargo Delivery for EMC}

The use of solar electric propulsion derived from the investment currently being made by NASA to support the Asteroid Redirect Mission (ARM) is a key ground rule for the EMC, maintaining consistency with several of the guiding principles of the Pioneering Space strategy. While the application of these high-power SEP technologies in the SEP Chemical architectures is restricted to the delivery of cargo to Mars, the impact is widespread. Predeployment of Earth return propulsion greatly reduces the number of MPCS required for the crew flights and the SEP can be repurposed after arrival at Mars to provide operational power for elements, such as the Phobos exploration habitat. The key to applying SEP to these missions is striking the right balance between high-efficiency and flight time.

\section{A. Evolution from ARM to Mars}

NASA is making significant technology investments in the development of the components of high power SEP systems. Currently being applied toward the Asteroid Redirect Mission (ARM), these high power solar arrays and thrusters are being developed with a focus on their extensibility to human missions in cis-lunar space and eventually at Mars. The current reference design of the ARM SEP stage utilizes $50 \mathrm{~kW}$ solar arrays at 1 AU providing $40 \mathrm{~kW}$ to the Electric Propulsion (EP) system. The propulsion system consists of four $13.3 \mathrm{~kW}$ magnetically shielded Hall thrusters operating in a 3+1 configuration with three active and one spare thruster. The bus is built to accommodate up to $10 \mathrm{t}$ of Xenon necessary to return mass from the range of asteroids currently under consideration as potential targets. All three of these areas, high power SEP thrusters and power processing, high power solar arrays and Xenon propellant storage, are extensible to the larger systems required for future human missions.

An example of an extensibility application is the current design work looking at the ARM Block 1a configuration. Designed to provide $150 \mathrm{~kW}$ power at 1 AU to power 11 ARM-class Hall thrusters in an 11+1 configuration, this spacecraft holds a minimum of $16 \mathrm{t}$ of Xe. While array size, additional thruster/power-processing unit strings and the additional Xe capacity all represent significant increases from the current ARM Block 1 bus, all of the components themselves are directly extensible from the technologies under development for ARM. Figure 4 illustrates the evolution from Block 1 to Block 1a as envisioned by the ARM program. 

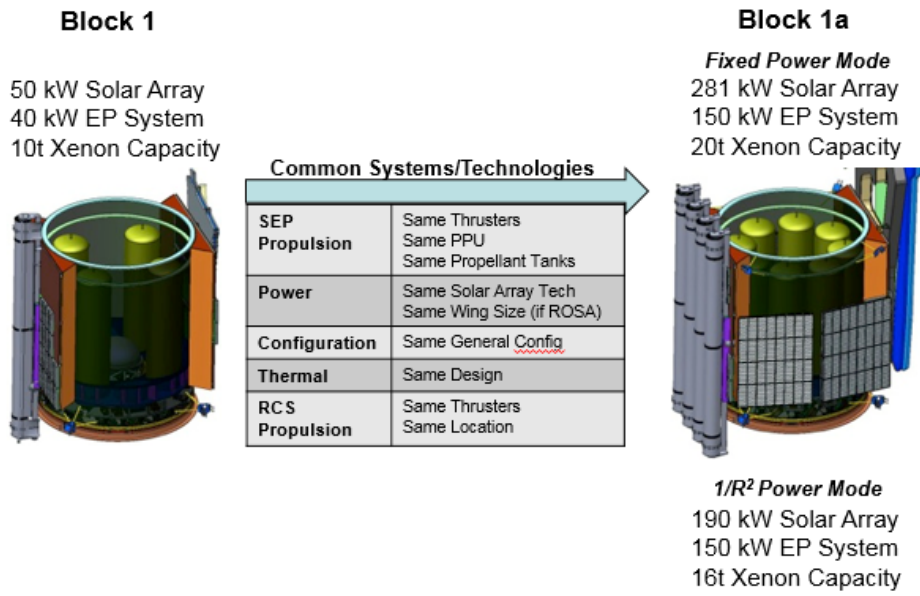

Figure 4. The Evolution of SEP. One current option for high-power SEP evolution involves a common bus approach to building the Block 1 ARV for the ARM mission and then adding additional power production and Xe storage capability to have a Block 1a configuration for future human spaceflight applications.

\section{B. Performance Trades}

As part of the evaluation of the EMC SEP Chemical architectures, analysis has been done on the use of the ARM derived Block 1a spacecraft in human Mars architectures. ${ }^{7}$ In order to continue to verify the trade space, further analyses examined the impact of delivering payload to Mars using the SEP stage assuming a power reduction to the EP system as a function of distance to the sun of $1 / \mathrm{R}^{2}$ versus assuming a constant power to the EP system independent of solar distance. Assuming a $1 / \mathrm{R}^{2}$ configuration in this case means that the solar array delivers full power to the EP system at $1 \mathrm{AU}$, and as the distance to the sun becomes greater than $1 \mathrm{AU}$, the power to the EP system reduces as a function of $1 / R^{2}$ where $R$ is the distance to the Sun. A constant power system assumes that the solar array is oversized at $1 \mathrm{AU}$ in order to deliver a constant power to the EP system as distance to the sun is increased greater than $1 \mathrm{AU}$. Analyses focused on the delivery of cargo payloads to 1 Sol orbit as well as aerocaptured lander payloads to different Mars arrival velocities.

For all of the analyses, it was assumed that the payload and the SEP stage were launched on a single SLS Block 2. No packaging assessments were completed for this conceptual analysis, and these will be completed in follow up activities. The SLS Block 2 delivers the combined stack to a low perigee elliptical orbit with an apogee as high as possible based on the combined mass of the SEP stage and its payload. Previous analysis limited the spiral at Earth to no greater than one year. This set a limit on the starting orbit into which the SLS delivered its payload. For the current set of trades, no limit has been assumed on the initial starting orbit and longer trip times for the Earth spiral were allowed in order to deliver the desired $45 \mathrm{t}$ aerocaptured lander to Mars. Using the ARM Hall thrusters, operating at an effective $\mathrm{I}_{\mathrm{sp}}$ of $3000 \mathrm{sec}$, the SEP stage spirals to a C3 of $-2 \mathrm{~km}^{2} / \mathrm{s}^{2}$ setting up a Lunar Gravity Assist (LGA) to reach interplanetary space with a C3 of $+2 \mathrm{~km}^{2} / \mathrm{s}^{2}$. Two months were allocated to the LGA maneuvers. After Earth escape, the SEP stage performs the interplanetary spiral to Mars. For the lander payloads, the SEP stage delivers a fixed lander mass to a specified Mars arrival velocity and after separating from the lander, swings by Mars. Future analysis will explore returning the SEP stage to Earth for reuse. For the other cargo payloads, the SEP stage performs a propulsive orbit capture, spiraling down to the desired Mars parking orbit.

The analysis results are shown in Table 4. It can be seen that for aerocapture cases where the SEP stage performs most of its primary propulsion closer to Earth, the $1 / \mathrm{R}^{2}$ configurations outperformed the constant power configurations in delivering the same mass to an entry condition in terms of trip time and propellant consumption. Essentially, by avoiding the spiral trajectory down into the Mars gravity well, carrying the extra mass for the oversized array is less optimal than using the smaller system sized to provide full EP power at 1AU. Conversely, for the delivery of cargo to a 1 Sol orbit, the constant power case outperforms the $1 / \mathrm{R}^{2}$ case in terms of trip time for the same cargo mass. If the SEP system must perform appreciable maneuvers at Mars distance to the sun, having the additional array area in order to operate the EP system at full power reduces the trip time to final insertion by over a year. 
Table 4. SEP Cargo Delivery Trade Results. Various trades are summarized reporting both propellant load required and trip times associated with various delivery conditions and SEP configurations.

\begin{tabular}{|c|c|c|c|c|c|c|c|c|c|c|c|c|c|}
\hline \multicolumn{5}{|c|}{ HAT Lander Delivery } & \multicolumn{5}{|c|}{ SLS2b-ASB Delivery Orbit } & \multicolumn{4}{|c|}{ Mission Summary } \\
\hline Case & Mission & $\begin{array}{c}\text { Nominal } \\
\text { Power } \\
(\mathrm{kW})\end{array}$ & $\begin{array}{l}\text { Power } \\
\text { Profile } \\
\end{array}$ & $\begin{array}{c}\text { Mars } \\
\text { capture } \\
\text { type* }\end{array}$ & \begin{tabular}{|c|}
$\begin{array}{c}\text { SLS delivery } \\
\text { date }\end{array}$ \\
\end{tabular} & $\begin{array}{l}\text { Perigee Alt } \\
(\mathrm{km})[\mathrm{Hp}]\end{array}$ & $\begin{array}{l}\text { Apogee Alt } \\
(\mathrm{km})[\mathrm{Ha}]\end{array}$ & $\begin{array}{c}\text { Inclination } \\
(\mathrm{km})\end{array}$ & $\begin{array}{l}\text { Delivered } \\
\text { Mass }(\mathrm{kg}) \\
\end{array}$ & $\begin{array}{l}\text { Total trip } \\
\text { (years) })^{* *}\end{array}$ & $\begin{array}{c}\text { Total SEP } \\
\text { propellant } \\
(\mathrm{kg})\end{array}$ & $\begin{array}{c}\text { Spacecraft } \\
\text { dry mass } \\
(\mathrm{kg})\end{array}$ & $\begin{array}{c}\text { Payload } \\
\text { system } \\
(\mathrm{kg}) \\
\end{array}$ \\
\hline $1 \mathrm{~A}$ & Mars Vinf $=3.907$; shortest trip & 150 & $1 / r 2$ & Aero & $2030 / 08 / 28$ & 200 & 24,430 & 28.50 & 64,916 & 3.25 & 12,029 & 7,687 & 45,200 \\
\hline 1B & Mars Vinf $=3.907$; shortest trip & 150 & const & Aero & $2030 / 03 / 13$ & 200 & 16,804 & 28.50 & 69,927 & 3.73 & 14,685 & 10,042 & 45,200 \\
\hline $2 \mathrm{~A}$ & Mars Vinf $=3.907$; shortest trip & 300 & $1 / r^{2}$ & Aero & $2030 / 04 / 22$ & 200 & 2,411 & 28.50 & 100,162 & 3.41 & 25,233 & 12,729 & 62,200 \\
\hline 2B & Mars Vinf $=3.907$; shortest trip & 300 & const & Aero & $2029 / 12 / 01$ & 200 & 575 & 28.50 & 111,305 & 3.84 & 31,329 & 17,776 & 62,200 \\
\hline $3 A$ & Mars 1 Sol; shortest trip & 150 & $1 / \mathrm{r} 2$ & SEP & $2030 / 02 / 15$ & 200 & 10,846 & 28.50 & 76,493 & 7.77 & 23,164 & 8,128 & 45,201 \\
\hline 3B & $\begin{array}{l}\text { Mars } 1 \mathrm{Sol} ; \text { shortest trip } \\
\text { Mars } 1 \mathrm{Sol} ; \text { max perf; }\end{array}$ & 150 & const & SEP & $2029 / 07 / 15$ & 200 & 6,622 & 28.50 & 84,828 & 6.34 & 28,869 & 10,759 & 45,200 \\
\hline $4 \mathrm{~A}$ & short of $P / L$ target $(62.2 \mathrm{mT})$ & 300 & $1 / \mathrm{r} 2$ & SEP & $2029 / 10 / 20$ & 200 & 355 & 28.50 & 112,938 & 9.54 & 39,058 & 13,540 & 60,339 \\
\hline $4 B$ & Mars 1 Sol; shortest trip & 300 & const & SEP & \multicolumn{9}{|c|}{ Cannot achieve (near) the desired payload } \\
\hline $5 A$ & Phobos; shortest trip & 150 & $1 / \mathrm{r} 2$ & SEP & $2030 / 06 / 20$ & 200 & 13,912 & 28.50 & 72,624 & 7.89 & 22,396 & 8,128 & 42,100 \\
\hline $5 B$ & Phobos; shortest trip & 150 & const & SEP & $2029 / 05 / 19$ & 200 & 5,995 & 28.50 & 86,469 & 7.31 & 33,361 & 11,008 & 42,100 \\
\hline $6 \mathrm{~A}$ & Phobos; shortest trip & 300 & $1 / \mathrm{r} 2$ & SEP & $2030 / 11 / 19$ & 200 & 5,962 & 28.50 & 86,560 & 5.12 & 31,356 & 13,104 & 42,099 \\
\hline $6 \mathrm{~B}$ & Phobos; shortest trip & 300 & const & SEP & $2030 / 11 / 27$ & 200 & 3,766 & 28.50 & 93,862 & 4.94 & 33,842 & 17,919 & 42,101 \\
\hline 1AA & Mars Vinf $=5.2$; shortest trip & 150 & $1 / \mathrm{r} 2$ & Aero & $2030 / 05 / 20$ & 200 & 20,586 & 28.50 & 67,109 & 3.39 & 14,222 & 7,687 & 45,200 \\
\hline $1 \mathrm{BB}$ & Mars Vinf $=5.2$; shortest trip & 150 & const & Aero & $2030 / 02 / 07$ & 200 & 14,612 & 28.50 & 71,858 & 3.70 & 16,562 & 10,097 & 45,200 \\
\hline $2 A A$ & Mars Vinf $=5.2$; shortest trip & 300 & $1 / r^{2}$ & Aero & 2029/12/07 & 200 & 1,377 & 28.50 & 105,940 & 3.63 & 30,696 & 13,044 & 62,200 \\
\hline $2 \mathrm{BB}$ & Mars Vinf $=5.2$; shortest trip & 300 & const & Aero & 2029/07/31 & 200 & 295 & 28.50 & 113,402 & 4.07 & 33,282 & 17,919 & 62,201 \\
\hline 1AAA & Mars Vinf $=0.5$; shortest trip & 150 & $1 / \mathrm{r} 2$ & Aero & 2030/10/01 & 200 & 18,490 & 28.50 & 68,477 & 4.31 & 15,590 & 7,687 & 45,200 \\
\hline \multicolumn{14}{|c|}{1 Sol mission trade: $150 \mathrm{~kW}$ vehicle with target payload system mass of $30,000 \mathrm{~kg}+3,000 \mathrm{~kg}$ (margin) } \\
\hline & Mars 1 Sol; shortest trip & & & & & & & & & & & & \\
\hline 3AA & SLS2b_ASB has excess perf & 150 & $1 / \mathrm{r} 2$ & SEP & $2031 / 09 / 12$ & 200 & 55,560 & 28.50 & 56,029 & 4.99 & 14,181 & 7,687 & 34,161 \\
\hline 3Bв & Mars 1 Sol; shortest trip & 150 & const & SEP & $2031 / 08 / 12$ & 200 & 44,756 & 28.50 & 58,016 & 3.36 & 14,975 & 10,042 & 32,999 \\
\hline \multicolumn{14}{|c|}{1 Sol mission trade: $300 \mathrm{~kW}$ vehicle with target payload system mass of $50,000 \mathrm{~kg}+3,000 \mathrm{~kg}$ (margin) } \\
\hline $4 A A$ & Mars 1 Sol; shortest trip & 300 & $1 / \mathrm{r} 2$ & SEP & $2030 / 04 / 27$ & 200 & 1,727 & 28.50 & 103,845 & 6.37 & 37,430 & 13,415 & 53,000 \\
\hline 4BB & Mars 1 Sol; shortest trip & 300 & const & SEP & $2030 / 05 / 21$ & 200 & 1,439 & 28.50 & 105,552 & 4.33 & 34,580 & 17,972 & 53,000 \\
\hline \multicolumn{14}{|c|}{$*=$ Aerocapture not modeled, simulation ends at targeted Vinf at Mars; SEP cap } \\
\hline$* *=b o$ & Id numbers indicate total trip ti & $500 d$ & & & & & & & & NASA / GRC/ & n/W. Sjac & $06-18-2$ & 07-23-15 \\
\hline
\end{tabular}

For the aerocapture analysis, two power levels of EP system were considered in order to bound the trade space. Previous analysis showed that for a single SLS launch of both the cargo and the SEP stage, the dry mass of SEP stages that used greater than $300 \mathrm{~kW}$ to the EP system begins to cut into the available mass for cargo. Therefore, 300 $\mathrm{kW}$ EP is the upper bound for the analysis. The Block 1a assumption of $150 \mathrm{~kW}$ EP power was used as the lower bound. The main consideration for the application of a $300 \mathrm{~kW}$ SEP spacecraft was the delivery of larger landers and thus, potentially reducing the number of landers required. While the results shown in Table 4 indicate that there is potential for a $300 \mathrm{~kW}$ system to deliver these larger landers, more analysis is planned to determine if a reduction in the SEP power level can achieve similar results with larger landers.

\section{SEP Stage Description for Mars}

For this architecture concept, the power level of the stage was chosen from the analysis in order to perform both the 45t aerocapture lander delivery and the MCPS delivery to 1 Sol. In order to deliver the MCPS within a reasonable time, the oversized version of the aerocaptured lander SEP stage was chosen. This is a nonoptimal application for the aerocaptured lander but this higher power will greatly reduce the final spiral at Mars for the MCPS delivery flights.

While the ARM Block 1a vehicle currently assumes $150 \mathrm{~kW}$ EP at 1 AU EOL which translates to $190 \mathrm{~kW}$ spacecraft power, the compromise SEP stage chosen for this architecture iteration assumes $150 \mathrm{~kW}$ EP constant power. This higher power requires $281 \mathrm{~kW}$ Spacecraft power at 1AU BOL. Additionally, this higher power system requires a Xe capacity of $\sim 20 \mathrm{t}$, which is higher than the assumed 16t of the Block 1a configuration. However, this constant power SEP stage still uses the same 11+1 EP thruster configuration as the block 1a. All technologies from the solar arrays, thrusters, and Xe tanks can trace back to the technology development for the ARM Block 1 concept design. A conceptual configuration is shown in Figure 5. 


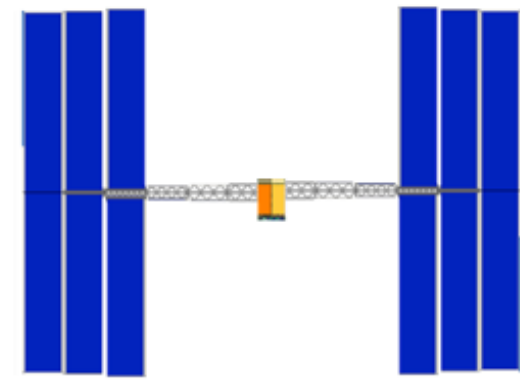

281 kW Solar Array

150 kW EP System

20t Xenon Capacity

Isp $=3000 \mathrm{~s}$

Total Thrust $\sim 5 \mathrm{~N}$

Figure 5. The Fixed Power SEP Configuration. The current baseline configuration for the cargo flight SEP spacecraft is a version of the Block 1a ARMderived spacecraft with solar arrays for $281 \mathrm{~kW}$ and a 20t Xe propellant capacity.

\section{Commonality of Methane: Crew Delivery for EMC}

At the center of the crew delivery approach of the SEP Chemical architecture is the Methane Cryogenic Propulsion Stage, or MCPS. This stage features 4 Liquid Oxygen, Liquid Methane (Lox/LCH4) engines each with a thrust of approximately 22,500 lbf. One key aspect of the SEP Chemical architecture is the delivery of the crew on a traditional conjunction-class trajectory, reducing in-space flight durations and increasing Mars stay time. These trajectories are only possible with the kind of high thrust burns provided by a chemical propulsion stage. Higher specific impulse is desired when operating in-space, which would typically lead designers to look at a hydrogenbased propulsion system. However the sustainability goal of the EMC puts focus on minimizing technology development and recurring costs. It is these considerations that have led to the decision to use a methane-based propulsion system, sacrificing some performance to gain sustainability.

\section{A. A Common Methane Engine}

Each element in a Mars campaign represents a unique project that will contribute development and production costs to the overall campaign cost estimate. Additional campaign cost is incurred for each new technology that must be developed to support the planned series of missions. Therefore, to build a sustainable architecture that is implementable in the near-term with the buying power of current budgets, the goal is to minimize both the number of unique elements and the number of technology development programs required. In the case of the SEP Chemical architectural approach, performance benefits are realized through the use of two different transportation technologies, the SEP for cargo and the MCPS for crew. Element design was leveraged in the definition of the MCPS to offset the penalties that are incurred by requiring the development of two unique in-space transportation elements.

One element that is commonly required across all potential Mars surface exploration missions is the lander. If it is desirable to have humans explore the surface of Mars then a vehicle must be developed to land them safely on the surface of Mars and return them to orbit. In support of the various Mars mission and architecture studies over the past decades, many lander design alternatives have been investigated. As in many of these previous studies, the EMC lander design team has determined that the propulsion system of choice for the Mars lander element is a methane engine. This engine and some general design specifications are shown in Figure 5. The selection of this engine and the specification of its performance values has a wide-reaching impact on the Mars campaign.

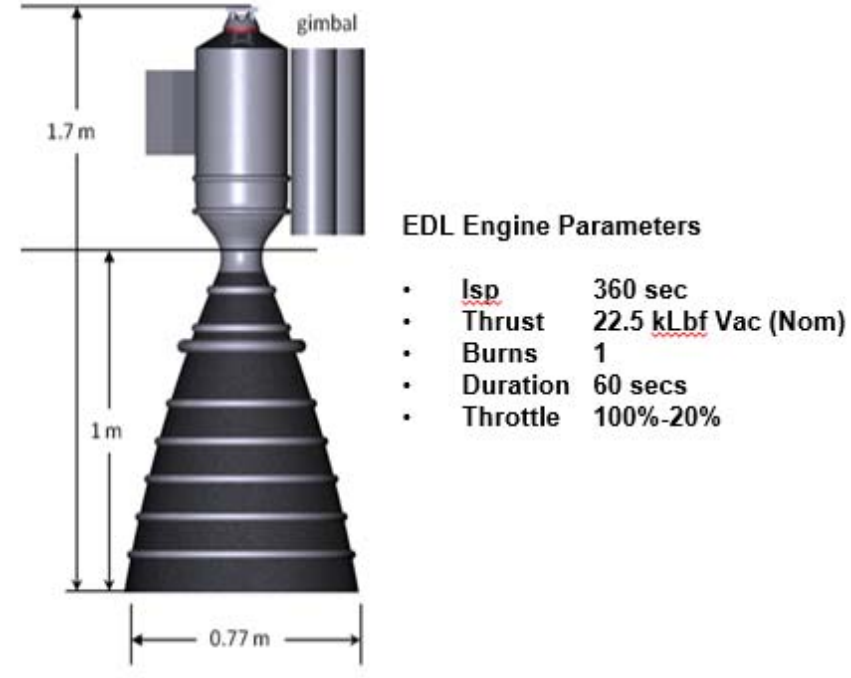

Figure 5. Common Methane Engine. This common methane engine is used on several elements within the EMC

11

American Institute of Aeronautics and Astronautics 
Engine development programs are expensive endeavors and, to minimize costs, the EMC has placed a focus on maximizing technology development investments wherever possible. In keeping with this general goal, the EMC team has surveyed all elements using chemical propulsion in the campaign and has determined that a common methane engine development program can serve several elements providing potentially significant cost savings.

Figure 6 provides a graphic representation of the methane engine commonality within the EMC. The lander elements, both the Mars Decent Module (MDM) and the Mars Ascent Vehicle (MAV), are required for all Mars surface missions and have been designed using methane propulsion. By extending those methane engines to the MCPS and the Mars Crew Taxi, the Mars program can leverage that investment and reduce the costs of those other elements. The application table shows which element drive the design requirements in each of the four major performance areas of the engine. The thrust level is determined by the needs of the MAV second stage and the MDM. Specific impulse is driven by the needs of the MAV second stage. Throttling is required for Mars landing and the Mars Crew Taxi requires four engine restarts. By combining these requirements a common engine can be developed to meet the needs of many of the elements required in the architecture.
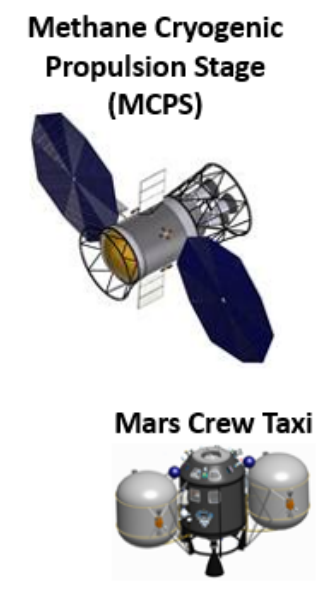
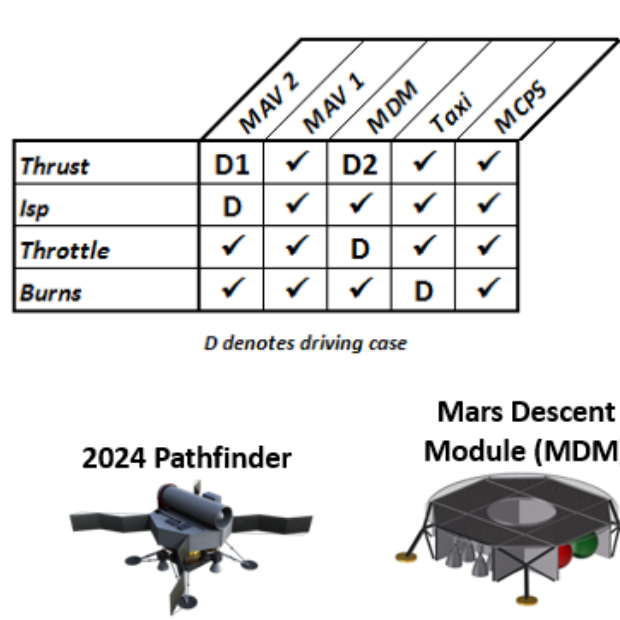
Module (MDM)

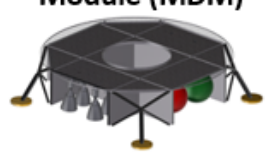

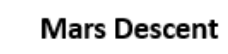

Mars Ascent Vehicle (MAV)
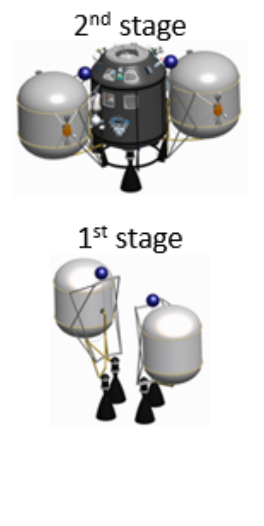

Figure 6. The Methane Elements. This set of mission elements drives the design of the common methane engine, defining thrust, Isp, throttle and burn requirements.

\section{B. The MCPS Stage Design}

The commonality of the LOx/LCH4 engines across the architecture provides several programmic benefits, as previously discussed. Several other common technologies will also be developed to support these elements. The storage of cryogenic propellants in deep space for long periods of time will require the development of a Cryo-Fluid Management (CFM) system. Cryo-coolers that maintain temperatures around $90 \mathrm{~K}$ will be a key technology required for this CFM system. While the implementation of CFM will be slightly different between in-space environments and Mars surface environments, development of key common components can be leveraged across the methane elements. The Reaction Control Systems (RCS) will also be common across these elements. A small methane thruster will be developed to enable a common propellant storage system. By pulling oxygen and methane directly from the main propellant tanks, the RCS system can be simplified and these elements can avoid the use of toxic hydrazine-based RCS systems. 
Figure 7 shows the current design configuration of the MPCS. The MCPS has a diameter of 4.2 meters and a length of 9.5 meters. The tanks are constructed of 2195 aluminum in a simple-to-manufacture monocoque configuration while the dry structure is 2219 aluminum. Dry structures in this design include the thrust structure as well as truss structures designed to serve as stage adapters to connect multiple stages. These truss structures also serve as launch adapters. The power system uses two 6.9 $\mathrm{m}$ diameter UltraFlex solar arrays to provide $5.4 \mathrm{~kW}$ of electrical power at Mars. The majority of this power is required for cryogenic propellant storage. Deployable radiators are also designed to support the heat rejection from the CFM system. The CFM system employs 90K cryo-coolers for the storage and conditioning of both the liquid oxygen and liquid methane.

The stage is designed with a full complement of guidance, navigation, and control sensors to support freeflying time during the assembly phase of the mission. This provides a level of redundancy for stacks with multiple stages and ensures that minimal stage customization will be required during manufacturing. The main propulsion system is made up of four $100,000 \mathrm{~N}(22,500 \mathrm{lbf})$ methane engines, common to the Mars lander. The Reaction Control System uses pressurized LOx/LCH4, providing a common propellant and avoiding the use of traditional

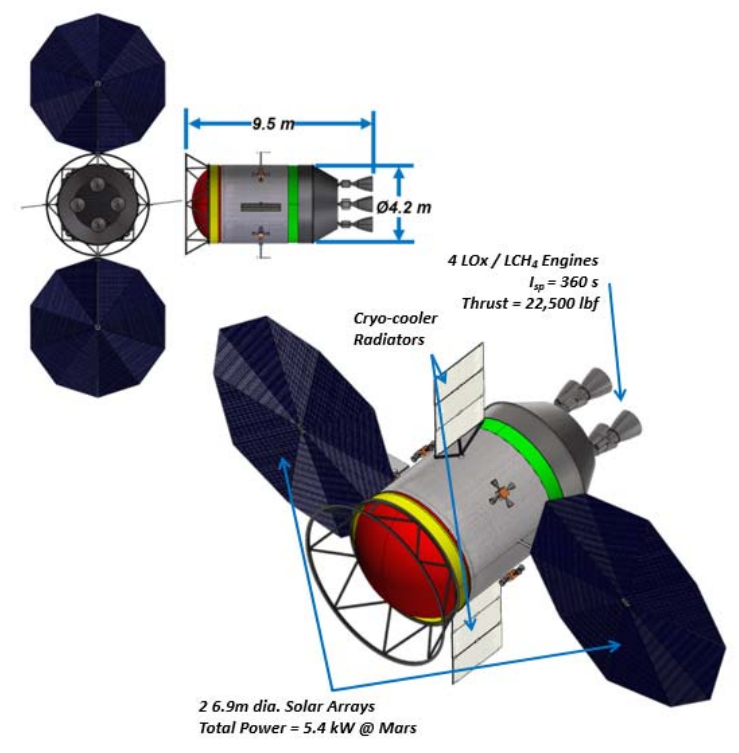

Figure 7. The MCPS. This in-space stage will deliver crew to Mars and return them to Earth. hypergolic propellants that require additional safety procedures for loading.

A fully loaded MCPS will have a mass of approximately $45 \mathrm{t}$, however the final mass of the designed stage is yet to be determined. For each architecture trade performed, the MCPS is resized to best match the particular propulsion requirements of that architecture configuration. This MCPS mass estimate is derived from several bottoms up design studies performed by the Advanced Concepts Office at NASA's Marshall Space Flight Center. Each bottoms up design study developed a configuration and mass estimate for various propellant loads, resulting in a mass estimating relationship that allows architecture analysts to vary the size of the stage to fit the needs of the architectures being investigated. Within an architecture option, a common stage design is assumed where the largest propellant load sized the stage and all other stages within the architecture are offloaded to accommodate specific burn requirements. Once an architecture is selected, a final design will be developed that serves all missions.

\section{High Thrust Trajectories for Crew Delivery}

A key benefit of the SEP Chemical approach to the EMC is combination of appropriate interplanetary trajectories for each Mars delivery function. Highly efficient SEP systems can move significant amounts of payload to Mars for a fraction of the propellant required by higher-thrust chemical propulsion systems. However, those lowthrust trajectories take a significant amount of time. By delivering the time-sensitive crew with high-thrust chemical propulsion, crew transit times can be reduced to minimize exposure to the zero-gravity, high-radiation conditions of deep space. Even within the high-thrust trajectory world, the interplanetary trip time is a function of the amount of energy expended during the various burns. Faster trip times can be achieved with by applying more $\Delta \mathrm{V}$ at either end of the flight.

The EMC crew trajectories balance trip time and stage performance, reducing stage size by finding lower $\Delta \mathrm{V}$ trajectories that still maintain reasonable crew trip times. This $\Delta \mathrm{V}$ reduction is achieved through the implementation of two key mission design approaches. First, the typically very high TMI burn $\Delta \mathrm{V}$ is greatly reduced through the selection of cis-Lunar space as the aggregation point for the crew flight stacks. The crew flights begin from an elliptical orbit with a very low perigee and an apogee at lunar distance. This high elliptical orbit maintains very high orbital energy, manifesting in high perigee velocities and greatly reducing the impulsive velocity change required to depart Earth for Mars. The second mission design approach used to minimize $\Delta \mathrm{V}$ was to investigate a sub-class of conjunction-class trajectories historically limited to the high-thrust delivery of payload to Mars. These trajectories take longer to transfer to and from Mars however, the trip time differential between these trajectories and the faster conjunction-class crewed trajectories is small. In the case of the EMC, the use of a slightly lower specific-impulse 
MCPS rather than the traditional hydrogen-based stage necessitated the trade of longer flight times for lower $\Delta \mathrm{V}$. In the three flights required to support the EMC the crew flight times are still less than 1 year. The $\Delta \mathrm{V}$ budgets, trip times, and a graphical representation of each crew flight are provided in Figure 8.

\begin{tabular}{|c|c|c|c|c|}
\hline \multirow{8}{*}{$\begin{array}{c}2033 \\
\text { Phobos } \\
\text { Mission }\end{array}$} & \multirow{4}{*}{$\Delta V(m / s)$} & TMI & 983 & \multirow{8}{*}{$\frac{\text { Earth Departure }}{04 / 09 / 2033}$} \\
\hline & & $\mathrm{MOI}$ & 1245 & \\
\hline & & TEI & 1095 & \\
\hline & & _EOI & 549 & \\
\hline & \multirow{4}{*}{$\begin{array}{l}\text { Flight } \\
\text { Time (d) }\end{array}$} & Outbound & 231 & \\
\hline & & Stay & 528 & \\
\hline & & Return & 198 & \\
\hline & & Total & 957 & \\
\hline \multirow{8}{*}{$\begin{array}{c}2039 \\
\text { Landing } \\
\text { Mission }\end{array}$} & \multirow{4}{*}{$\Delta V(\mathrm{~m} / \mathrm{s})$} & TMI & 692 & \multirow{8}{*}{$\frac{\text { Mars Arrival }}{09 / 07 / 2040}$} \\
\hline & & $\mathrm{MOI}$ & 888 & \\
\hline & & TEI & 989 & \\
\hline & & EOI & 513 & \\
\hline & \multirow{4}{*}{$\begin{array}{l}\text { Flight } \\
\text { Time (d) }\end{array}$} & Outbound & 350 & \\
\hline & & Stay & 329 & \\
\hline & & Return & 298 & \\
\hline & & Total & 977 & \\
\hline \multirow{8}{*}{$\begin{array}{c}2043 \\
\text { Landing } \\
\text { Mission }\end{array}$} & \multirow{4}{*}{$\Delta V(\mathrm{~m} / \mathrm{s})$} & TMI & 547 & \multirow{8}{*}{$\frac{\frac{\text { Mars Departure }}{\text { OB/18/2045 }}-\cdots}{\text { TOF }_{\text {out }}=289 \text { days }} \frac{\text { Earth Departure }}{11 / 11 / 2043}$} \\
\hline & & MOI & 1082 & \\
\hline & & TEI & 630 & \\
\hline & & EOI & 1427. & \\
\hline & \multirow{4}{*}{$\begin{array}{l}\text { Flight } \\
\text { Time }(d)\end{array}$} & Outbound & 289 & \\
\hline & & Stay & 358 & \\
\hline & & Return & 356 & \\
\hline & & Total & 1003 & \\
\hline
\end{tabular}

Figure 8. High Thrust Trajectories. The three crew flights performed by a series of MCPS deliver the crew to Mars and back to Earth in 2033, 2039, and 2043

Another key difference between the crew flights assumed in the EMC and many of the previous Mars architecture studies is the use of an Earth Orbit Insertion burn at the end of the mission to propulsively return the crew and transit habitat into orbit. Not only does this maneuver support the reuse of the transit habitat but it also eliminates a requirement to carry the Orion capsule to Mars and back. In most human Mars missions, the crew is directly returned to the Earth's surface through the use of an Earth entry vehicle that must fly to Mars with the crew. In current architectures, that Earth entry vehicle would be the Orion capsule. However, modifications to the Orion heat shield would be required to withstand the higher Earth entry velocities associated with a Mars return. Propulsive capture at Earth enables the use of the current Orion design. Capture into the LD-HEO further reduces the EOI $\Delta V$. Finally, through the use of SEP to pre-deploy the Earth return propulsion, the propulsion requirements for the return leg of the flight are decoupled from the Mars-bound leg of the flight. This allows mission designers to increase the energy requirement for Earth return without seeing the traditionally large impact to the number of stages required for Earth departure, thus keeping the overall number of stage required for the crew flight low.

\section{Mission \& Operations Trades}

During the last year, many trade analyses have been completed to probe the mission and operational trade spaces in the context of the EMC and the broader Pioneering Space strategy. Within the SEP-Chemical set of architecture options, several trades have yielded interesting results, some of which will inform the trades and sensitivities assessed in the coming year of analysis. This section provides a summary of a few of the more interesting trades performed this year. 


\section{A. SEP Delivery to 1 Sol}

When pre-deploying elements to Mars using SEP stages, both trip time and power level become key design considerations. The duration of the cargo flights will drive the flight coordination of the entire campaign and has an impact on the need date of various elements in the architecture. The longer the cargo flights take, the earlier the payloads are required which will drive element development schedules. Power level required for the SEP stage will drive the cost and size of the stage. Ultimately, trip time is driven by a combination of thrust and mass, with lighter payloads and higher SEP power level resulting in faster trips to Mars. While the relationship between payload mass and trip time appears intuitive, the relationship between power and trip time is slightly more complex.

The typical SEP cargo flight to Mars can be broken into three phases. The duration of the Earth spiral phase is mainly driven by SEP power level and SLS lift capacity. Earth spiral time is reduced as SEP power level is increased. However, it is the initial orbit altitude that determines how far the SEP must fly to escape Earth. This altitude is driven by SLS performance, with heavier payloads being delivered to lower apogee orbits and resulting in longer Earth spiral times. The interplanetary phase is where the high-efficiency SEP excels. The Mars capture phase represents a significant challenge to the SEP cargo vehicle. SEP flight operations within a gravity environment will always benefit from additional power but Mars is 1.5 AU away from the Sun, leaving significantly less power available when flying spiral trajectories in the Martian gravity well. Flight time improvements in this phase can be made either by increasing the solar array area of the SEP spacecraft or by avoiding the Mars spiral phase and leaving the payloads to perform their own orbit insertion maneuvers.

As previously mentioned, SEP power level was traded to evaluate the impacts to SEP performance for the cargo pre-deploy flights. A fixed power profile with arrays sized to provide full thruster power at Mars results in arrays sized to generate $281 \mathrm{~kW}$ of power at Earth. This profile was traded against the $1 / \mathrm{R}^{2}$ power profile where the arrays are sized to deliver $150 \mathrm{~kW}$ of thruster power at Earth and the power available to the thrusters decays with the inverse square of the distance from the sun as the spacecraft makes its way to Mars. A comparison of these two configurations is provided in Figure 9. Results showed that the fixed power profile outperformed the $1 / \mathrm{R}^{2}$ profile when Mars spiral flight was required but that the $1 / \mathrm{R}^{2}$ power profile was the leading candidate when allowing payloads to perform their own Mars orbit insertion.

While this result was shown for the delivery of landers that were designed for aerocapture, an integrated extension of the trade was performed to include impacts to the MCPS delivery flights. The MCPS is capable of performing a propulsive capture into the desired parking orbit at Mars but the stage mass will increase to accommodate the additional propellant required. This growth can be minimized by reducing the Mars arrival velocity using the SEP stage, thus reducing the MOI $\Delta \mathrm{V}$. For example, a Mars arrival velocity of $0.5 \mathrm{~km} / \mathrm{s}$ will reduce the 1 Sol orbit insertion $\Delta \mathrm{V}$ to $260 \mathrm{~m} / \mathrm{s}$, a value well within the range of the MCPS RCS thrusters. The larger stage mass and additional $\Delta \mathrm{V}$ required to achieve the low Mars arrival velocities increase the work load of the SEP stage and an integrated trade was performed to determine the net effect of delivering the MCPS using this method.
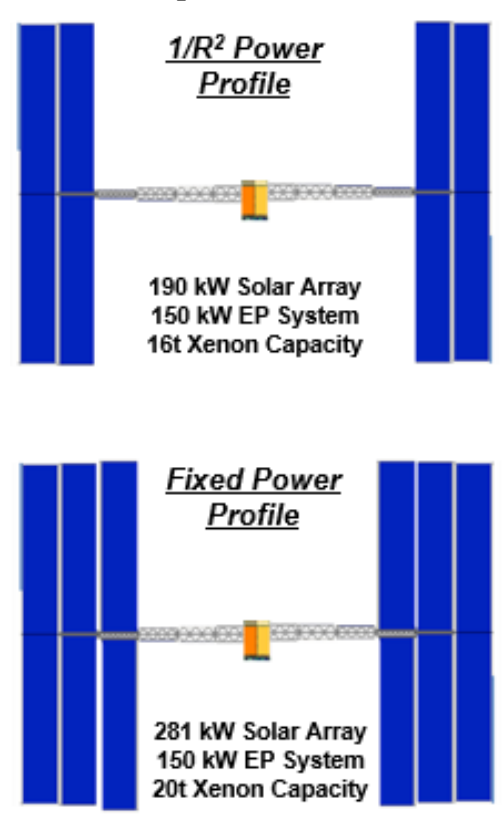

Figure 9. Alternate Configurations. The fixed power profile spacecraft requires $91 \mathrm{~kW}$ more power than the $1 / R^{2}$ spacecraft but can save trip time. 


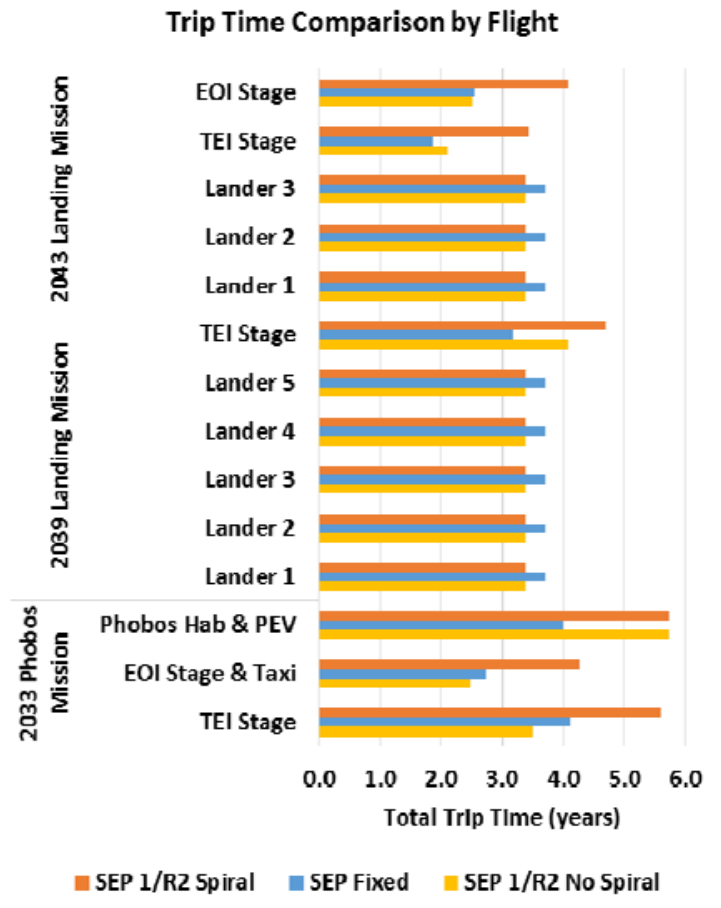

Figure 10. SEP Delivery Trade Results. Total trip time for the 14 cargo pre-deploy mission trading Mars arrival approach.
The results of this trade can be seen in Figure 10. The $1 / R^{2}$ power profile requires enough solar arrays for $190 \mathrm{~kW}$ of power at $1 \mathrm{AU}$. These arrays provide power to the thrusters, housekeeping power for the spacecraft bus, and account for degradation of the arrays due to radiation exposure. In these cases, the MCPS delivery flights can take from 3.5 to 5.5 years with $500-800$ days spent spiraling into the final 1 Sol orbit at Mars. The fixed power profile requires $91 \mathrm{~kW}$ more power than the 1/R2 configuration, which allows the spacecraft to provide full thruster power at Mars. This extra thrust can reduce Mars spiral times by 400 to 500 days, depending on the size of the payload. The fixed power configuration saves approximately 2500 days of total trip time across the 14 pre-deployment missions. It is important to note, however, that the lander delivery flights do take 114 days longer with the fixed power configuration most likely due to the increase in SEP spacecraft inert mass from the weight of the additional solar arrays. Alternatively, by eliminating the Mars spiral completely and placing the requirement on the MCPS to perform MOI, an overall savings of approximately 2700 days of total trip time is realized. This estimated savings will be investigated further in future studies, but preliminary results look promising. This architectural approach would keep the SEP stage at 190 $\mathrm{kW}$, keeping the solar arrays small, while showing similar trip time reductions as those shown with the fixed power profile. With both the fixed power configuration and the no Mars spiral architecture, the MCPS delivery times range from 2 to 3.5 years.

\section{B. Aggregation in LDRO}

Many of the flights to Mars in the SEP-Chemical architecture require the aggregation of several elements in space prior to Earth departure. The EMC has ground ruled the use of the LDRO for these aggregation operations, planning to leverage infrastructure already in place from the ARM and other cis-Lunar proving ground missions for support. LDRO aggregation has several advantages including a significant $\Delta \mathrm{V}$ reduction for Earth departure over the traditional, LEO aggregation schemes of past proposed Mars architectures. Each element is boosted most of the way out of the Earth's gravity well by the large SLS Block 2 launch vehicle, minimizing the additional energy required to complete the Earth departure maneuver.

There is, however, one additional operation required when aggregating in LDRO; insertion into and departure from the LDRO. A significant operational and functional trade completed as part of the SEP-Chemical architecture trade analyses was a trade of the method for LDRO insertion for each of the elements launched for aggregation. Two insertion methods and two functional solutions were investigated. Through extensive evaluation of the LDRO across NASA, two general methods for inserting into the LDRO have been refined; the slow insertion method and the fast insertion method. As their names imply, these two methods trade $\Delta \mathrm{V}$ for trip time. Schematics of the two methods are shown in Figure 11. The slow insertion method involves several lunar swing-by maneuvers and takes advantage of solar perturbation effects the edge of the Earth's sphere of influence to perform the LDRO insertion maneuver in approximately 200 days for approximately $120 \mathrm{~m} / \mathrm{s}$ of $\Delta \mathrm{V}$. The fast insertion method performs one powered lunar swing-by maneuver and one insertion burn and takes approximately 9 days and $340 \mathrm{~m} / \mathrm{s}$ of $\Delta \mathrm{V}$ to complete. 


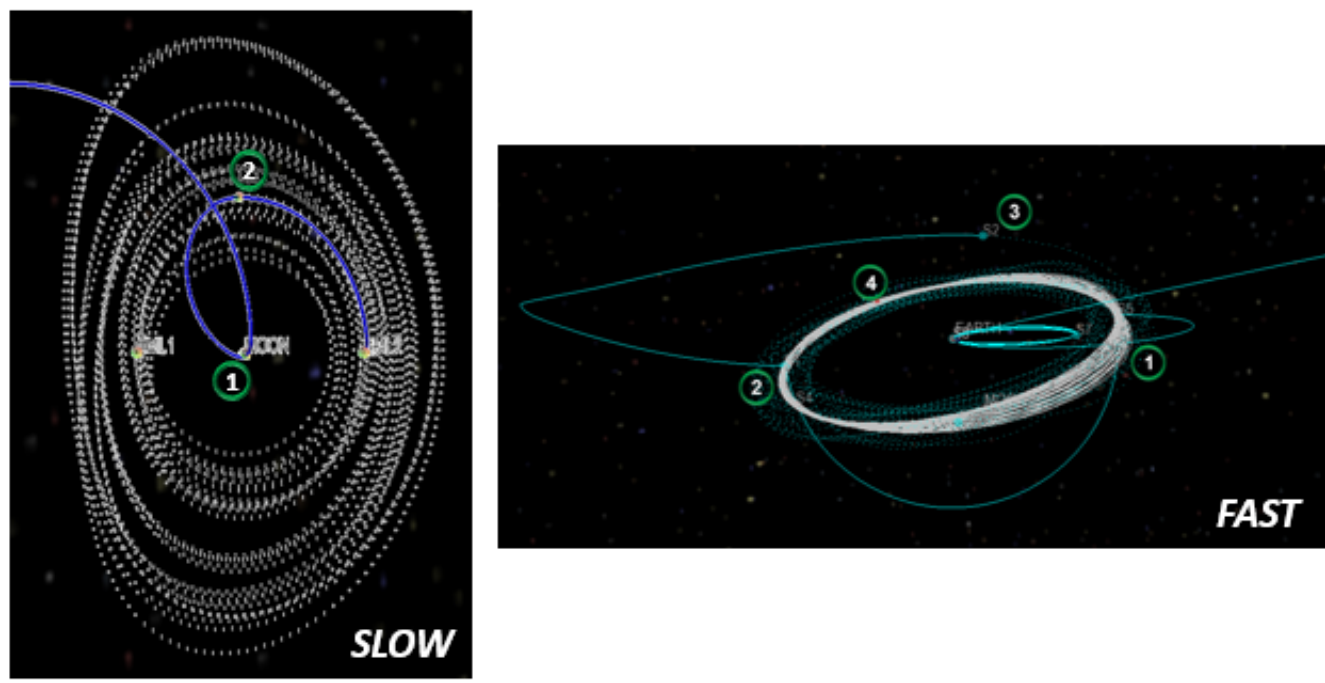

Figure 11. LDRO Insertion Options. Both the fast insertion (left) and the slow insertion (right) techniques were considered for the delivery of elements to the aggregation point in LDRO.

The functional trade for LDRO insertion was between the payloads providing their own $\Delta \mathrm{V}$ for insertion or developing a shepherding spacecraft that would guide the payload into LDRO and perform the insertion burns. While the shepherding spacecraft does eliminate a burn requirement for the payloads, it would be considered an additional element and would add to the overall cost of the Mars program if it only served the Mars vehicles. In the baseline architecture, only two mission elements, the MCPS and the transit habitat, would require insertion into LDRO. Choosing first to evaluate the impact to these elements of having them provide their own LDRO insertion, the propellant loads were evaluated for the slow and fast insertion for both the transit hab and the various MCPS required for the missions. The transit habitat requires nearly $1700 \mathrm{~kg}$ of propellant for the slow insertion and 4800 $\mathrm{kg}$ of propellant for the fast insertion. A small propulsion system is being designed into the general habitat design to support Phobos habitat operations and it was determined that the same sized propulsion system could support the $1700 \mathrm{~kg}$ propellant load of the slow LDRO insertion for the transit habitat. It was determined that the $4800 \mathrm{~kg}$ required for the fast insertion would be unnecessarily large and the slow insertion approach was decided on for the transit hab. The additional 200 days of operational time have been added to the aggregation operations assumptions for the EMC campaign team.

The MCPS impact yielded a different conclusion. The propellant requirement for the fast insertion ranges from $3000 \mathrm{~kg}$ to $4500 \mathrm{~kg}$ depending on the propellant loading for the stage in question. For a slow insertion, the propellant load ranges from $1000 \mathrm{~kg}$ to $1600 \mathrm{~kg}$. However, in this case, it was determined that the significantly shorter flight time of the fast insertion was desirable to maintain a reasonable cadence for the aggregation operations. The additional propellant required for the fast insertion did not adversely affect the overall design or operation of any of the MCPS required over the campaign and the fast insertion was baselined for the delivery of all propulsion stages to the aggregation point. Since all of these elements already had propulsion systems capable of performing these maneuvers, it was decided that an additional spacecraft for shepherding these elements into the LDRO was unnecessary.

\section{MCPS Design Sensitivity}

As currently designed, the fully loaded MCPS has a propellant mass fraction (PMF) of approximately 0.8. Many factors contribute to this value including the requirement to carry large solar arrays to operate the CFM systems at Mars and the requirement for additional mating structure to stack several stages for the flights to and from Mars. However, comparisons to other in-space stages from previous design studies and those currently fielded, including the upper stages for the Delta IV and Atlas V launch vehicles, indicate that this may be a conservative mass estimate. A first order investigation of architecture performance sensitivity to PMF was completed to determine if mass reduction efforts were work pursuing at this time.

The mass of the MCPS has a ripple effect throughout the entire architecture. In addition to traditional stage sizing mission dependencies, the impact of the stage mass to pre-deployment flight times is one unique to the SEP- 
Chemical architecture concept. To evaluate stage mass improvements, the architectures were evaluated using an adjusted stage dry mass that was artificially reduced from the stage mass indicated from the bottoms up design analysis results. This stage mass reduction does not presupposed a particular source of the mass reduction nor does it assume that the mass reduction is even achievable at this time. Rather, this is an academic exercise to determine if more time and effort should be spent at this time on MCPS mass reduction.

The impacts of mass reduction varied across the three mission opportunities of the EMC. In the 2033 flight opportunity, a PMF improvement from 0.8 to 0.85 resulted in a $33 \%$ reduction in pre-deployment time for each of the two pre-deployed stages. In the 2039 flight opportunity, the same mass improvement resulted in a reconfiguration of the Earth return propulsion stages such that both the TEI and EOI burns could be completed by a single stage with only a 180 day increase in the pre-deployment flight time. This would eliminate one MCPS from the architecture, reducing the total from 12 to 11 . In the 2043 opportunity, a PMF of 0.85 resulted in a single stage Mars transit system, completing both the TMI and MOI burns, thus eliminating another MCPS from the architecture. In all, the mass improvement could reduce the number of MCPS from 12 to 10 and reduce the number of SLS launches from 32 to 30 across the three mission campaign. Such an increase in PMF would require an 18\% reduction in the dry mass of the MCPS. While mass savings must be continually investigated in the context of these architecture trades, such a modest performance improvement for such a significant reduction in mass indicates that the MCPS mass reduction will not yield a large enough improvement to warrant detailed investigation at this time.

\section{Future Trade Studies}

The work presented in this paper provides a snapshot of the current state of the SEP Chemical transportation analyses. The transportation analysis team plans to continue the trade and sensitivity work in the coming year. More detailed investigations will be completed relating to MCPS delivery at Mars, potentially shifting the baseline architecture from a constant-power SEP configuration back to a smaller configuration by using the MCPS to perform Mars orbit insertion. Reusability trades will also be performed to identify places in the campaign where SEP stages may be flow back to Earth and reused on subsequent pre-deployment flights. Trajectories will continue to be refined as will Mars system operations, to fully understand the sensitivities associated with selecting different transportation schemes.

\section{Conclusions}

The EMC is intended to be an ongoing framework for trade analyses aimed at better defining the potential paths to Mars exploration in the context of NASA new Pioneering Space strategy. Sustainability is a main focus as is leveraging current and future technology investments to promote affordability and to build on prior successes. The SEP Chemical transportation architectures remain true to these goals by leveraging SEP technology investments from the ARM mission to perform all of the cargo pre-deployment flights. The commonality of the methane engine further promotes cross pollination of ideas from the various elements within the Mars architecture, reducing element development costs and promoting reliability. The baseline architecture presented meets the mission goals of the EMC, delivering human to the Martian system in the early 2030s and landing a crew on the surface of Mars in 2039. Trades performed to date indicate that LDRO is a viable aggregation point for mission elements and that MCPS mass reduction efforts may be premature at this time but can provide some benefits if viable design alternatives are identified. The Mars arrival trades show that there are multiple viable alternatives for delivering cargo to Mars and work will continue in this area to determine the best overall approach to balancing payload delivery capability and flight time. The transportation architecture team continues to support the analysis goals of the EMC to help develop an intelligent pathway to Mars that informs near term technology decisions to support long term Pioneering Space goals that lead to Earth independence and the continued expansion of human exploration in the solar system.

\section{Acknowledgments}

The authors would like the acknowledge the support received from both the COMPASS concurrent design team at NASA's Glenn Research Center and the Advanced Concepts Design Team at NASA Marshall Space Flight Center. We would also like to recognize the contributions of Waldy Sjauw at NASA Glenn for performing all of the low-thrust trajectory modeling and SEP performance evaluations and Dan Thomas at NASA Marshall for contributing all of the high-thrust trajectory analysis for the crew delivery flights. 


\section{References}

${ }^{1}$ Drake, Bret, (ed.), “Human Exploration of Mars Design Reference Architecture 5.0”, NASA SP-2009-566, July, 2009.

${ }^{2}$ Merrill, R.G., Chai, P., Jones, C.A., Komar, D.R., and Qu, M. “An Integrated Hybrid Transportation Architecture for Human Mars Expeditions,” AIAA Space 2105, Pasadena, CA, 2015.

${ }^{3}$ Chai, P., Merrill, R.G., and Qu, M. "Mars Hybrid Propulsion System Trajectory Analysis, Part 1: Crew Missions,” AIAA Space 2105, Pasadena, CA, 2015.

${ }^{4}$ Howe, S., Gernhardt, M., Lee, D., Crues, E. Abercromby, A., Chappell, S., and Nguyen, H. "Small Body Hopper Mobility Concepts,” AIAA Space 2105, Pasadena, CA, 2015.

${ }^{5}$ Polsgrove, T., Thomas, H.D., Stephens, W., and Rucker, M.A. "Mars Ascent Vehicle Design for Human Exploration,” AIAA Space 2105, Pasadena, CA, 2015.

${ }^{6}$ Toups, L., and Hoffman, S. "Pioneering Objectives and Activities on the Surface of Mars," AIAA Space 2105, Pasadena, CA, 2015.

${ }^{7}$ Percy, T. P., McGuire, M., and Polsgrove, T. “Combining Solar Electric Propulsion and Chemical Propulsion for Crewed Missions to Mars” IEEE Aerospace 2015, Big Sky, MT, 2015. 